\title{
As salas de cine na obra de Manuel Rivas ${ }^{1}$
}

\author{
Movie Theaters in Manuel Rivas's Work \\ Salvador Castro Otero \\ IES de Rodeira, Cangas do Morrazo \\ salvaclase64@hotmail.com \\ Recibido: noviembre de 2017. Aceptado: enero de 2018
}

Resumo: O presente artigo analiza as mencións ás salas de cine na obra de Manuel Rivas e intenta demostrar que o uso deste espazo ten un valor moi superior ao referencial pois sérvelle para expresar as emocións máis intensas e a beleza transcendente da realidade.

Palabras chave: Manuel Rivas; espazo cinematográfico; literatura e cinema; literatura comparada.

Abstract: This article offers an analysis of cinemas as they are mentioned in Manuel Rivas's works. It also tries to demonstrate/ that the use of this spatial. holds a much higher value than usual because it is used to show both more intense emotions and all the beauty emerging from reality.

Key words: Manuel Rivas; spatial frame; literature and cinema; comparative literature.

Cine, cine, cine.

Más cine por favor que toda la vida es cine y los sueños cine son.

(Luis Eduardo Aute)

Os ollos son coma un filme invertido que se proxecta fóra do cuarto escuro da mente.

(Manuel Rivas, A corpo aberto)

\footnotetext{
${ }^{1}$ Este artigo é un resumo dun apéndice da miña tese de doutoramento sobre «Manuel Rivas e o cine» defendida na Universidade de Vigo e dirixida por Carmen Becerra Suárez.
} 


\section{INTRODUCIÓN}

A sala de cine, para unhas cantas xeracións, converteuse nun lugar de encontro. Nela tiñan cabida, como ilusión ou como realidade, o amor e os conflitos. Aute expresábao moi ben na súa canción «Las cuatro y diez»: «Entonces te besé/ aquella fue la primera vez/ tus labios parecían de papel/ y a la salida en la puerta/ nos pidió un triste inspector nuestros carnets». Por iso, despois da desaparición de tantos cinemas, non debe estrañar que no relato de Marsé (2003) ou na canción Serrat (1987) os personaxes do cine ocupen, ao xeito de pantasmas, o cine Roxy aínda que xa se transformara nunha sucursal bancaria. Dalgún xeito toda sala de cine era un Cinema paradiso, un lugar e unhas imaxes para, como naquela fiestra que ollaba León Felipe (1981: 31) nunha vila da Alcarria, sentir que «Todo el ritmo de la vida pasa/ por este cristal de mi ventana...» Âs veces o cine trae «demasiada verdade» (Rivas 2010b: 69), di un dos personaxes de Todo é silencio sobre o neorrealismo, mais sempre fabrica soños, por iso, cando a realidade parece transcender a mediocridade do cotiá, a pequenez da rutina, o autor emprega o cine para explicala mellor, de aí que o ceo da Coruña pode ser «un cinema de estorninos» (Rivas 2008d: 21) ou un río un cinema de color.

Se cadra, antes de comezar o noso percorrido polas salas de cine que habitan nas páxinas de Rivas, conveña falar do concepto do espazo, pois, do mesmo xeito que os biólogos e os químicos falan da existencia de catro elementos esenciais para a vida: carbono, hidróxeno, osíxeno e nitróxeno, os teóricos da literatura (Becerra 2002: 25) adoitan considerar: narrador, tempo, espazo e personaxes os compoñentes estruturais esenciais dos relatos.

Para os amantes da literatura, A Mancha de Don Quixote, o Dublín de Ulises, o deserto de Comala, Macondo, Yoknapatawpha ou a Selva de Esmelle non son meros referentes xeográficos, simples decorados dunha narración, son verdadeiros personaxes, entes «vivos», en íntima relación cos seres que os habitan. Como negar este feito despois de ler La saga/fuga de J.B. e notar como Castroforte de Baralla levita ao compás e ao «descompás» das subidas ou baixadas anímicas dos seus moradores; como tapar os ollos e os oídos a unha taiga que súa na néboa ou chora na choiva e se reivindica como xente en Derzú Uzalá, a novela de Arséniev, case como se fose unha irmá da fraga de Cecebre de $E l$ bosque animado de Fernández Flórez. O espazo, mesmo cando parece apenas un lugar, pode ser o eixo estrutural dunha novela como no caso de Hijo de hombre de Roa Bastos ou A vida, instrucións de uso de Georges Perec. A pesar desta riqueza marabillosa - talvez deberiamos dicir, parafraseando a Alejo Carpentier $^{2}$, real marabillosa—; o espazo, como apunta Carmen Becera (2002: 25), é o elemento que menos «interés ha despertado en la crítica».

Non obstante, xa na antigüidade clásica, os teóricos da retórica se ocuparan deste tema. Para eles, o orador debería posuír cinco capacidades básicas: a inventio (capacidade para crear argumentos), a dispositio (capacidade para dis-

\footnotetext{
${ }^{2}$ Citado en Benedetti (1995:370).
} 
tribuílos axeitadamente), a elocutio (capacidade para elixir os xeitos máis elegantes e adecuados de expresión), a actio ou pronutiatio (capacidade para a modulación axeitada do discurso, mediante as inflexións de voz, momentos e acenos oportunos) e a memoria (capacidade para lembrar o discurso).

Unha das cuestións que, dentro da inventio, tiña que elaborar o orador para producir un verdadeiro e profundo discurso era $u b i$ ? Ubi non era unicamente o lugar da acción, moitas veces aportaba valores máis alá dos referenciais; podía converterse nunha verdadeira marca xenérica, por exemplo nas églogas. Outras, a elección dos escenarios da acción debía estar en consonancia co estado de ánimo ou as peripecias polas que transitaba os protagonistas; así, os loci amoeni - lugares idílicos- $e$ os loci eremi - lugares ermos, desérticos, hostís-, non expresaban unicamente a morfoloxía dun lugar senón ao tempo as emocións dos protagonistas e a intensidade da acción.

Ao longo do tempo foron aparecendo moitas outras formulacións sobre o concepto do espazo. $\mathrm{Bal}^{3}$, por exemplo, distinguiu entre lugar e espazo, primeiro indicaría a posición xeográfica, en tanto que o segundo expresaría o lugar vinculado a un punto de vista; Chatman (1990: 65-66) entre tempo da historia e tempo do discurso. Estas e outras diferenciacións son enormemente valiosas e fecundas pero unha análise detallada de todas elas excedería con moito a extensión e o sobre todo a intención deste traballo.

Mais parécenos esencial aclarar que do mesmo xeito que Ferdinand de Sausurre (1980: 67 e ss.) nos advertiu do carácter mental do fonema, da diferenza esencial entre este e a súa realización, debemos ter en conta que, o espazo literario non existe fóra do texto. É unha creación verbal, o resultado da experiencia individual, por ende abstracta, que o lector realiza a partir da lectura.

Para empezar, y con intención de desterrar desde ahora mismo posibles errores, es necesario apresurarse a advertir que el espacio literario no existe más que en el texto en virtud de las palabras, es, por tanto, un espacio verbal que se constituye como objeto del pensamiento y, en consecuencia, es el resultado de una experiencia individual. (Carmen Becerra (2002: 26)

En opinión de Carmen Becerra (2002) o espazo ten tres funcións significativas:

1. A primeira sería a descritiva, aquela que expresa o lugar onde acontecen os feitos.

2. A segunda a de organizar o material narrativo. Esta función non se limitaría a facilitar a coherencia e cohesións coa creación dunha memoria textual e co que Barthes ${ }^{4}$ chamou «efecto realidade» senón que tamén pasaría a ser a base compositiva de moitos xéneros como podería ser o western, a ciencia-ficción, a novela gótica ou a novela grega.

\footnotetext{
3 Citado en Tarrío (1998: 214).

${ }^{4}$ Citado en Tarrío (1998: 215).
} 
3. A terceira a de caracterizar ideolóxica e/ou psicoloxicamente. Así as diferenzas lonxe/próximo, pechado/aberto, arriba/abaixo, etcétera, poden estar mostrando unha determinada imaxe do mundo, unha ideoloxía; están a sinalar relacións non espaciais como clase social, protección, indiferenza, etc. Do mesmo xeito que o habitat define, en certo modo, ao animal que o ocupa, tamén o espazo discursivo pode caracterizar a quen o transita, pensemos, por exemplo, en La lluvia amarilla, a novela de Julio Llamazares. A aldea abandonada e inhóspita, en constante degradación, non é senón a expresión do interior en certo modo moribundo do único personaxe que a habita na perpetua soidade, por máis simpatía que teñamos pola súa loita pola supervivencia e a do seu mundo. Por outra banda, o espazo pode adquirir, dentro desta función caracterizadora, un certo matiz irónico cando os personaxes non se axeitan ao lugar no que están. Consideremos, por citar un só caso, ao policía aragonés das novelas de Domingo Villar e as súas dificultades para entender as peculiaridades idiomáticas dos galegos.

Volvamos agora ás salas de cine. Foi a principios de novembro de 1895 (Cabo Villaverde e Sánchez García, 2012: 35) cando Max Sklandanowsky realiza no Wintergarten de Berlín, un local de variedades, as primeiras proxección públicas de imaxes fotográficas en movemento en Europa, unha exhibición realizada co seu bioscopio. En decembro do mesmo ano, os irmáns Lumière, inventores do cinematógrafo, presentan no Gran Café de París as súas primeiras películas no que para moitos constitúe o nacemento do cinema. Un ano despois en 1896, no Koster\&Bial de Nova Iorque, unha sala dedicada ao music hall tiña lugar a presentación en sociedade do vitascopio de Thomas A. Edison. En España as primeiras proxeccións terán lugar no Circo Parish de Madrid en maio de 1896 e en Galicia será en setembro dese mesmo ano no Teatro-Circo coruñés.

O nacemento do espectáculo cinematográfico espertou un grande interese entre as masas polo que foi necesario habilitar espazos para a súa contemplación. Ao principio construíronse barracas en solares baleiros e tamén se aproveitaron locais destinados a outros mesteres como os teatros (foi o caso do Teatro-Circo da Coruña, o Teatro Principal de Pontevedra ou o Circo Tamberlick de Vigo) ou como os locais dos espectáculos de variedades (o Salón García de Vilagarcía de Arousa e o Salón París coruñés).

Do mesmo xeito que nos séculos XVI e XVII en Europa proliferaron os edificios dedicados ás representacións teatrais, o éxito da sétima arte, durante o s. Xx provocará a necesidade de construír salas para uso exclusivo ou principal, do espectáculo cinematográfico. Este impulso é contemporáneo á aparición do art nouveau ou modernismo como resulta patente en edificios como O Ideal Cinema de Vigo, o Kiosko Alfonso, ou o Teatro Linares Rivas da Coruña.

En coincidencia coa etapa de esplendor do cine silente, os edificios comezan a ter un estilo máis ecléctico, en xeral seguindo modelos clásicos pero sen renunciar á monumentalidade. O Teatro García Barbón de Vigo ou o Rosalía de Castro de Santiago poderían ser uns bos exemplos. 
Entre 1930 e 1939 vai primar o estilo que Cabo Villaverde e Sánchez García (2012) denominan: «Movemento moderno ou racionalismo» ${ }^{5}$. Entre as súas manifestacións poderiamos destacar o Cine Savoy da Coruña e o Gran Teatro de Lugo.

Durante o franquismo, a característica máis salientable nos cines galegos, xunto coa especial atención á fachada, empregada como anuncio, vai ser que os edificios están exentos, é dicir, separados do resto, o que lles outorga singularidade. As salas ocuparán, ademais, zonas centrais das vilas e cidades, confirmando a relevancia social deste espectáculo. O estilo é ecléctico e variado como podemos observar en edificios tan diferentes como o Teatro Colón da Coruña ou o Gran Teatro de Lugo ou o cine Yago de Ourense.

A partir dos anos 60 a construción de novas salas, en Galicia, foi moi escasa. En 1978 ábrese, na Coruña, o Valle-Inclán, o primeiro minicine da nosa Comunidade. Dende ese momento, a moda deste tipo de locais, con diversas salas pequenas que proxectan diferentes películas, vai ser dominante. Este proceso rematará coa inauguración de salas nos Centros Comerciais vixente nestes momentos e que expresa a integración do cine na sociedade de consumo.

Pero o salón cinematográfico, para o creador literario, é moito máis que o depositario dunha rica e variada práctica arquitectónica ao longo dos últimos 120 anos por fermosa que esta sexa. Constitúe, sobre todo, un universo complexo que lle permite manifestar unha variedade ampla de actividades e de emocións humanas. No local de cine aparecen, como quedou dito, os conflitos humanos como a loita de clases (pensemos na escena de Cinema Paradiso (Giuseppe Tornatore, 1988) en que os ricos cuspen sobre os pobres) ou os encontros clandestinos do amor como fermosamente relata Carlos Casares na súa novela Deus sentado nun sillón azul:

Pola tarde foron a ver $O$ rapaz, de Charlot. Pasaron o tempo que durou a película apertados un contra o outro, rozando de cando en vez a fronte e as meixelas. Ao chegar a escena na que o neno e o mendiño se ven obrigados a separarse por decisión das autoridades, cando arrinca a camioneta e o rapaciño, rodeado de policías e demais xentes da beneficencia que veñen a buscalo, estende os brazos cara ao vagabundo, ela sentiu que na súa man a humidade inesperada dunha lágrima. Sorprendida e contenta, achegouse a el e bicouno. El devolveulle un bico na meixela, rozándolle a boca, e deixaron de mirar a pantalla ata que o acomodador se achegou a el e lle dixo en voz baixa que ou se comportaban con decencia ou se vería obrigado a chamar á policía por escándalo (p. 98)

As salas convértense, dalgún xeito, nunha sorte de aleph borgeano, pois, a través da pantalla, varios tempos e lugares conviven no mesmo punto do uni-

5 Oriol Bohigas (citado na obra de Cabo Villaverde e Sánchez García) denominouno «racionalismo ortodoxo»e e «racionalismo á marxe». 
verso. A interactuación entre o espectador e a pantalla, como veremos, pode ser moi intensa e non só a través da catarse emocional, polo desafogar das emocións. A pantalla chega a transformar os espectadores, a modificar a súa visión do mundo.

\section{AS SALAS DE CINE NA OBRA DE MANUEL RIVAS}

Na obra de Rivas, os locais, aparezan baixo a etiqueta xenérica «cine» ou co nome propio, serven para mostrarnos unha complexa realidade que latexa ao seu arredor. Na nosa opinión, as informacións proporcionadas nas citas, poden clasificarse en catro grandes apartados: as referencias aos edificios, á actitude do público, aos conflitos humanos e á beleza do mundo

\subsection{O edificio}

Neste apartado incluiremos aquelas alusións que constitúen unha simple mención da sala, un uso toponímico da mesma, unha enumeración ou descrición das partes e das características, condicións e usos do local.

\section{a. Simple mención da sala}

Hai tempo que non vou ao cinema. As boas películas son todas tristes. (En salvaxe compaña, p. 44)

Nos ires e vires da cadea, trataba ao carcereiro coma se fose o acomodador dun cine. (O lapis do carpinteiro, p. 24)

Arrefriar os cines no verán, e quentalos no inverno. (Os libros arden mal, p. 63)

\section{b. Uso toponímico do edificio}

Ían por Atocha Alta, cara ao cine Hércules. Puxéronse contra a parede, a carón da entrada, en posición de combate. Cada un para loitar coa súa sombra. (Os libros arden mal, p. 120)

Cheo de extras saídos dos momentos menos chistosos das películas de Charlot que eu ía ver no cinematógrafo do Kiosko Alfonso, moi perto de alí (En salvaxe compaña, p. 56)

Dunha pelexa na praza de Vigo, á saída do cine Equitativa, na que se viran cunha cadea de bicicleta como arma. (Os libros arden mal, p. 438)

${ }^{6}$ Queremos sinalar que as mencións de Rivas son moi copiosas e que, por razóns de espazo reduciremos a unhas poucas as citas. 
c. Tipo de sala

Así que ao saír do minicine, pregunto, como de pasada que qué tal a película. (Muller no baño, p. 228)

A metade do curso, Kodac convencérao para facérense socios do Cineclub dos Dominicos. (Todo ben, p. 67)

O porteiro coxo da Sala $\mathrm{X}$ do meu barrio/ tamén se laiaba da escasa clientela ante os reclamos/pornográficos. (Do descoñecido ao descoñecido/ Ningún cisne, p. 216)

\section{d. Partes do local}

De socate, e foi algo máis que unha ilusión, vin a miña nai cun traxe de lunares a mirar enfeitizada o cartel dunha película, Camarote de lujo, coido que era na fachada ${ }^{7}$ dun cine. (O máis estraño/As chamadas perdidas, p. 289)

Rumbo puña en orde o pequeno ambigú no fondo, no lado contrario do escenario, e nun espazo con luz máis discreta. (Todo é silencio, p. 70)

Choraba Charo A'Rubia e até pareceu que o Spencer Tracy deixaba a zanfona para mirar con mágoa saudosa o patio de butacas. ( $O$ máis estraño/Ela maldita alma, p. 240)

Estabamos de pé nas butacas de veludo roído do vello cine Monelos. (As voces baixas, p. 161)

Unha vez, no cine, alguén tirou un gato dende o galiñeiro. Sería o tolo de Antas. Desfixo a película. Non sabes ti o complicado que é cazar un bo gato. (Todo é silencio, p. 193)

As tardes dos venres/ o ciclista chegaba con carteis do cine Portazgo no paquete/ e o cubo de cola colgando do guiador. (Do descoñecido ao descoñecido, p. 218)

\section{e. Características ou carencias do local}

Non había calefacción en ningunha parte. Nin na casa, nin na escola, nin na igrexa. Tampouco no cine. Mais no cinematógrafo era distinto. A pantalla facía de braseiro. Se o que existe non é a temperatura, senón a sensación climática, o cine era un cálido pavillón botánico onde eramos felices como durmideiras verdes. (A corpo aberto, p. 112)

\section{Climático?}

$\mathrm{Si}$, climático. Arrefriar os cines no verán, e quentalos no inverno. E instalar grandes frigoríficos por todo o país para que sempre haxa que comer. (Os libros arden mal, p. 63)

\footnotetext{
7 Os subliñados son nosos.
} 


\section{f. Usos do local}

Pero el gran esperado de la noche es, cómo no, Xosé Manuel Beiras. Ha llenado el cine Rega, a pesar de que la televisión transmite el partido del superdepor. (Galicia, el bonsái atlántico, p. 185)

Dende aquí sae un desvío, en costa, que leva a un pequeno outeiro onde se ergue o Ultramar, pousada, bar, tenda e adega, co seu anexo de salón de baile e cinema París-Noitía. (Todo é silencio, p. 21)

[No] cine Monelos. Bailábamos ás ceibas Los chicos con las chicas. (As voces baixas, $\mathrm{p} .161$ )

A primeira vez que viu unha película no salón, que era tamén o de bailar pensou que Moby Dick estaba alí de certo, no cadro cambiante do seu mar. ( $O$ máis estraño/ As chamadas perdidas, p. 298)

\subsection{A actitude do público}

Nas salas de cine, os momentos máis celebrados polos espectadores de Galopíns de pacotilla, a última de Woody Allen, son os lapsus linguae. (Muller no baño, p. 160)

Até que chegou un día en que o único espectador berrou en voz alta: «Convertiches o cine noutro cemiterio!» (A corpo aberto, p. 82)

Trouxo varias veces Capitáns intrépidos e a da vida de Thomas Alva Edison. Cando inventaba o filamento da luz aplaudía todo o cine. (Todo é silencio, p. 68)

Choraba Charo A'Rubia e até pareceu que o Spencer Tracy deixaba a zanfona para mirar con mágoa saudosa o patio de butacas.( $O$ máis estraño/Ela, maldita alma, p. 240)

O cinema enteiro imitaba como unha liberación o ruxido do león da Metro. (As voces baixas, p. 151)

Gustaríame acuñar moeda propia/ co rostro do boxeador/ ou a cara de Marisol,/ a mociña que eu amaba/ na escuridade do cinema. (A desaparición da neve, p. 51)

Na ficción, o público do cinema seguía con atención o diálogo. Algún espelido botouse a rir. (Todo ben, p.70)

\subsection{Os conflitos humanos}

Outra proba da liberación de costumes nesta vila lucense, con fama de conservadora, é a carteleira do único cine, o teatro Vilalbés. Pola tarde, El barrendero, de Cantinflas. Pola noite botan unha película «S». (Galicia, Galicia, p. 326) 


\subsection{A beleza do mundo}

No cinema do ceo da Coruña, durante o día, os estorniños movíanse en nubes sen acougo. Secuencias fílmicas dunha fasquía expresionista. (Os Grouchos, p. 21)

A verdade é que, cando penso en escenarios dunha posíbel película de terror, o primeiro que me vén á cabeza é unha desas moitas granxas de cría intensiva, de engorde compulsivo... (A corpo aberto, p. 295)

En canto ó Gran Canón do Colorado, o galego non lle queda máis remedio que poñer un punto sobre o i. «Home, está ben para unha película. Pero morres de sede, che.» (Galicia, Galicia, p. 312)

\section{O ESPAZO-PANTALLA NA OBRA DE MANUEL RIVAS}

Aínda que ás veces apareza como un mero soporte da imaxe — «Agora adoitan preguntarme: ¿Que sentes ao ver A lingua das bolboretas nunha pantalla de cine? Supoño que esperan que me exprese en termos de traizón ou fidelidade do filme en relación co texto.» (Muller no baño, p. 57)—ou como reflexo dunha crítica social $-\ll \mathrm{O}$ mundo exterior é unha gran pantalla que conspira contra os inocentes.» (Unha espía no reino de Galicia, p. 68)-, na obra de Rivas a palabra pantalla navega sempre sobre o mar sorprendente da fascinación. A pantalla, acolledora de imaxes, espazo onde as luces e as sombras se mesturan para permitirnos o goce doutros mundos, provoca que un lugar sexa múltiple. Pode incluso transformarse en metáfora da realidade. Moito se ten comentado sobre a arte como imitación da vida (a mímese aristotélica), e da arte como anticipación da realidade, pero a beleza do real, por efecto da súa propia fermosura, transformase en cine; a natureza é contemplada como nun filme e a chuvia ou o mar van «copando a pantalla ata que entras na súa frecuencia» (Os comedores de patacas, p. 62):

Un día do outono, xusto un día, vanse as moscas e vén a chuvia. O aire comeza a reolverse á altura dos pés. Os animais póñense ao axexo. Algo pasa na pedra e na madeira. De súpeto, polos cumes do Faro e do Castelo, asoma o exército imperial. Primeiro bravamente, a canonazos, con lampexos de lóstregos. Logo en forma de ráfagas, dacabalo do vento, durante meses agochado coma un bandido tras os Regatiños dos Congos. E máis tarde, mansa e teimosa, vai copando a pantalla ata que entras na súa frecuencia, unha tristura entumecida. Entón é cando escoitas todos os laios con nitidez ferinte. (Os comedores de patacas, p. 62)

O mar foi sempre unha inmensa pantalla cara á que se orientaba o mundo do val, pousando con esmero como un coxín de funda bordada e con pompóns, na cadeira de alto respaldo dos montes penedíos. ( $O$ máis estraño/ As chamadas perdidas, p. 297)

Sen eles o saber, fixeron o amor para ela na pantalla do mar. ( $O$ máis estraño/ As chamadas perdidas, p. 299) 
Claro que, por veces, a ollada dos humanos non pode contemplar a beleza escondida, por iso, a pantalla pode mostrar o ollar doutro ser vivo.

As rosas brancas, ventureiras, da estrada do Castro a Elviña, son miúdas e semella que todo o esforzo non é por medrar senón por recender, e podes non velas, agochadas, tímidas como están ás veces na pantalla dos mirtos, mais soben á cabeza de lonxe e enchen o lugar. (Os libros arden mal, p. 251)

Tamén as obras humanas, cando parecen superar a beleza do ordinario, se reflicten na pantalla, como unha forma de sublimarse:

Mais ela, a atención posta na pantalla do altar, luminosa, florida, varas de narciso na mesa do sagrario, rosas, gladíolos, e moitos caraveis brancos, vermellos e xaspeados, tamén en orla na saba do comulgatorio. (En salvaxe compaña, p. 129)

Rivas, como Hitchcock ou Angelopoulos, concibe o cinema como un arte de olladas, e tamén, como o mestre do suspense, concede grande importancia as ventás, de modo que non resulta sorprendente que unha fiestra deveña en pantalla.

O sarxento García, tan falangueiro, ficou mudo coma se a ventá fose unha pantalla de cine. (O lapis do carpinteiro, p. 138)

Preguntouse se aquelas abellas que chuchaban nas flores brancas da maceira eran das súas colmeas ou se viñan da horta de Gandón. Gustaba do café ben quente e moi doce pero a xícara se lle fora arrefriando nas mans, distraído pola pantalla da fiestra. (O máis estraño, p. 208)

A pantalla adquire pois sentires: «Non é certo que a pantalla ature todo o que lle boten.» ( A corpo aberto, $p$. 148) e a vida, a forza de ser extraordinaria, acada a forma do cinema.

Como se se tratase dunha homenaxe a $O$ moderno Sherlock Holmes de Buster Keaton ou en A rosa púrpura do Cairo de Woody Allen, o autor coruñés tamén consegue que a pantalla interactúe co espectador, así en Os libros arden mal, podemos ler:

Os ollos coa luz de ollos do que facía de Drácula, que aínda queimou a pantalla do cine Hércules, dous buracos deixou alí, como queimaduras de cigarro. (p. 720)

Rivas realiza unha verdadeira exhibición da súa habilidade para describir os personaxes a través de imaxes cinematográficas, os ollos coa luz de Lugosi, no seu papel de Drácula ${ }^{8}$, son demoníacos, malvados. Pero o autor, como os direc-

${ }^{8}$ Esta mesma metáfora vaia empregar para referirse ao expresidente do goberno español, José María Aznar, de quen di que «exercía unha atracción temerosa, sobre todo en partidarios e subalternos, similar ao efecto «luz de ollos» de Bela Lugosi en Drácula (1931)» (A corpo aberto, 207) 
tores citados, vai máis alá e rompe as barreiras entre as realidades ao describir como a ollada do personaxe dun filme deixa pegadas físicas na pantalla: a ollada do actor causa uns buratos. Outro exemplo desta interacción atopámolo no seguinte parágrafo: «E alí estabamos todos, dixo Antonio Ventura, metidiños no escuro do cine Rex, encollidos nas butacas, coas lapas da pantalla lambéndonos a cara.» (O máis estraño, p. 239)

É certo que son as lapas, destelos naturais da luz, pero a personificación sinestésica marcada polo verbo lamber transforma a relación entre o contemplador e o contemplado ata o extremo de causar unha intimidade física, que serve ademais como pórtico para o paroxismo emocional de Charo A'Rubia que virá a continuación. Por último non podemos esquecer como a pantalla e o cine facían elevar a temperatura emocional e mesmo física a partir da elevación do termómetro anímico:

Non había calefacción en case ningunha parte. Nin na casa, nin na escola, nin na igrexa. Tampouco no cine. Mais no cinematógrafo era distinto. A pantalla facía de braseiro. Se o que existe non é a temperatura, senón a sensación climática, o cine era un cálido pavillón botánico onde eramos felices como durmideiras verdes. (A corpo aberto, p. 111-112)

\section{CONCLUSIÓNS}

Do mesmo xeito que denominamos homo dixitalis cada un dos integrantes da xeración nacida cando a tecnoloxía informática estaba desenvolvida e espallada a, a xeración que recibiu a maioría dos relatos de ficción na escuridade do cinema (e posteriormente da televisión) podería ser definida como homo filmicus. A asistencia ao espectáculo cinematográfico supuxo para este grupo humano unha actividade social moi intensa que acollía, ademais, moitas outras experiencias humanas, de modo que as salas de cine foron o seu escenario. Por iso resultan comprensibles as moitas alusións dos autores dese tempo ás mesmas.

As salas de cine na obra de Manuel Rivas aparecen citadas como simples decorados da acción, como topónimos localizadores, como lugares onde un público expresa as súas opinións e sentimentos pero tamén como unha metáfora, como un símbolo, do máis fermoso e intenso que poden observar e sentir os humanos. Cando Rivas quere sublimar a beleza da natureza, das creacións humanas, recorre ao cinema.

A pantalla, singular espazo que nos permite acoller a un tempo lugares alleos e múltiples, pode en ocasións albergar pegadas, mesmo físicas, do mundo da ficción e expresar así a unidade, case a comuñón, emocional entre as incorpóreas imaxes e a carnalidade do espectador. Este recurso constitúe un valioso e orixinal recurso estilístico do escritor de Monte Alto. 


\section{BIBLIOGRAFÍA}

Becerra Suárez, C. (2002) «Aproximación al estudio del espacio: el espacio literario y el espacio fílmico» Boletín Galego de Literatura, 27, pp. 2538.

Benedetti, M. (1995) El ejercicio del criterio, Madrid, Alfaguara.

Cabo Villaverde, J. L. + Sánchez García, J. A. (eds.) (2012) Cines de Galicia. A Coruña, Fundación Barrie.

Chatman S. (1990) Historia y discurso. La estructura narrativa en la novela y el cine. Madrid, Taurus.

Felipe, L. (1981) Versos y oraciones del caminante, Madrid, Visor.

Marsé, J. (2003) «El fantasma del cine Roxy», Cuentos completos, Madrid, Espasa Calpe, pp. 35-76.

Rivas, M. (1994) Galicia, el bonsái atlántico. Descripción del Antiguo Reino del Oeste. Madrid, El País Aguilar.

Rivas, M. (1999) Galicia, Galicia, Vigo, Xerais

- (2000) A man dos paíños, Vigo, Xerais.

- (2002) Muller no baño, Vigo, Xerais.

- (2003) Do descoñecido ao descoñecido. Obra poética (1980-2003). A Coruña, Espiral Maior.

- (2005a) O lapis do carpinteiro, Vigo, Xerais.

- (2005b) O heroe. Vigo, Xerais.

- (2006) Os libros arden mal, Vigo, Xerais.

- (2008a) En salvaxe compaña, Vigo, Xerais.

- (2008b) A corpo aberto. Vigo, Xerais.

- (2008c) Os comedores de patacas, Vigo, Xerais.

- (2008d) Os Grouchos. Vigo, Xerais.

- (2009a) Episodios galegos. Tempos de esperpento, Vigo, Xerais.

- (2009b) A desaparición da neve. Madrid, Alfaguara.

- (2010a) Todo ben. Vigo, Xerais.

- (2010b) Todo é silencio. Vigo, Xerais.

- (2011) O máis estraños. Contos reunidos, Vigo, Xerais.

- (2012) As voces baixas, Vigo, Xerais. 
Saussure, F. de (1980) Curso de lingüística general, Madrid, Akal.

Serrat, J. M. (1987) «Los fantasmas del Roxy», Bienaventurados (ábum musical). Madrid, Ariola.

Tarrio Varela, A. (dir.) (1998) Diccionario de termos literarios. Santiago de Compostela, Centro Ramón Piñeiro, Xunta de Galicia. 
